\title{
TOXECON RETROFIT FOR MERCURY AND MULTI-POLLUTANT CONTROL ON THREE 90 MW COAL FIRED BOILERS
}

Quarterly Technical Progress Report

\author{
Reporting Period: April 1, 2004 - June 30, 2004
}

\author{
Prepared By \\ Richard E. Johnson \\ Wisconsin Electric Power Company \\ 333 West Everett Street \\ Milwaukee, WI 53203
}

July 30, 2004

DOE Cooperative Agreement No.: DE-FC26-04NT41766

Theodore J. McMahon, USDOE Project Officer 


\section{DISCLAIMER}

This report was prepared as an account of work sponsored by an agency of the United States Government. Neither the United States Government nor any agency thereof, nor any of their employees, makes any warranty, express or implied, or assumes any legal liability or responsibility for the accuracy, completeness, or usefulness of any information, apparatus, product, or process disclosed, or represents that its use would not infringe privately owned rights. Reference herein to any specific commercial product, process, or service by trade name trademark, manufacturer, or otherwise does not necessarily constitute or imply its endorsement, recommendation, or favoring by the United States Government or any agency thereof. The views and opinions of authors expressed herein do not necessarily state or reflect those of the United States Government or any agency thereof. 


\section{ABSTRACT}

With the Nation's coal-burning utilities facing tighter controls on mercury pollutants, the U.S. Department of Energy is supporting projects that could offer power plant operators better ways to reduce these emissions at much lower costs. Sorbent injection technology represents one of the simplest and most mature approaches to controlling mercury emissions from coalfired boilers. It involves injecting a solid material such as powdered activated carbon into the flue gas. The gas-phase mercury in the flue gas contacts the sorbent and attaches to its surface. The sorbent with the mercury attached is then collected by a particle control device along with the other solid material, primarily fly ash.

WE Energies has over 3,700 MW of coal-fired generating capacity and supports an integrated multi-emission control strategy for $\mathrm{SO}_{2}, \mathrm{NO}_{\mathrm{x}}$ and mercury emissions while maintaining a varied fuel mix for electric supply. The primary goal of this project is to reduce mercury emissions from three $90 \mathrm{MW}$ units that burn Powder River Basin coal at the WE Energies Presque Isle Power Plant. Additional goals are to reduce nitrogen oxide $\left(\mathrm{NO}_{\mathrm{x}}\right)$, sulfur dioxide $\left(\mathrm{SO}_{2}\right)$, and particulate matter (PM) emissions, allow for reuse and sale of fly ash, demonstrate a reliable mercury continuous emission monitor (CEM) suitable for use in the power plant environment, and demonstrate a process to recover mercury captured in the sorbent. To achieve these goals, WE Energies (the Participant) will design, install, and operate a TOXECON ${ }^{\mathrm{TM}}$ (TOXECON) system designed to clean the combined flue gases of units 7, 8, and 9 at the Presque Isle Power Plant.

TOXECON is a patented process in which a fabric filter system (baghouse) installed down stream of an existing particle control device is used in conjunction with sorbent injection for removal of pollutants from combustion flue gas. For this project, the flue gas emissions will be controlled from the three units using a single baghouse. Mercury will be controlled by injection of activated carbon or other novel sorbents, while $\mathrm{NO}_{\mathrm{x}}$ and $\mathrm{SO}_{2}$ will be controlled by injection of sodium based or other novel sorbents. Addition of the TOXECON baghouse will provide enhanced particulate control. Sorbents will be injected downstream of the existing particle collection device to allow for continued sale and reuse of captured fly ash from the existing particulate control device, uncontaminated by activated carbon or sodium sorbents.

Methods for sorbent regeneration, i.e. mercury recovery from the sorbent, will be explored and evaluated. For mercury concentration monitoring in the flue gas streams, components available for use will be evaluated and the best available will be integrated into a mercury CEM suitable for use in the power plant environment. This project will provide for the use of a novel multi-pollutant control system to reduce emissions of mercury and other air pollutants, while minimizing waste, from a coal-fired power generation system. 


\section{TABLE OF CONTENTS}

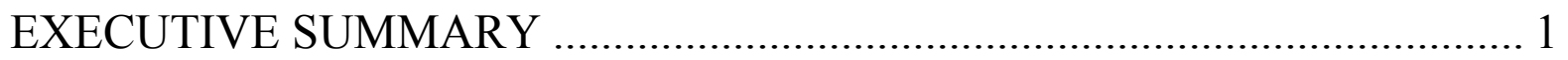

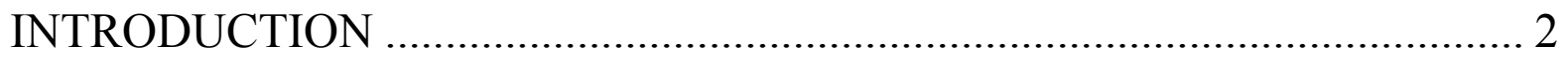

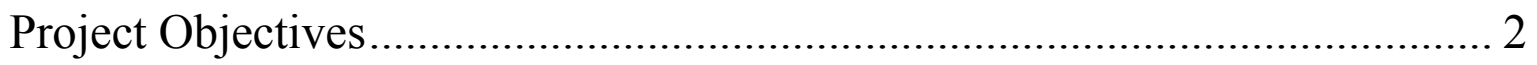

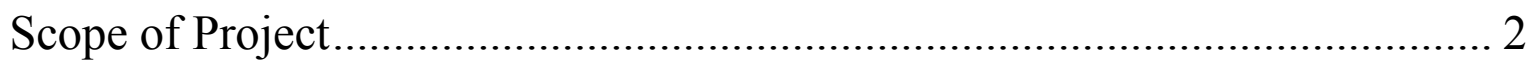

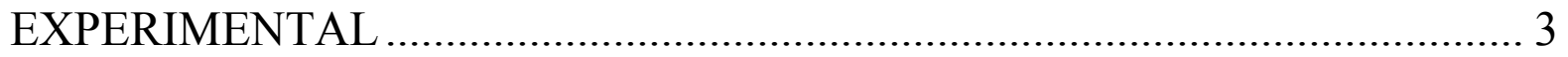

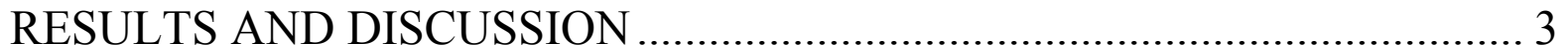

Task 1 - Design Review Meeting ................................................................. 5

Task 2 - Project Management Plan ............................................................... 5

Task 3 - Provide NEPA Documentation, Environmental Approvals

Documentation and Regulatory Approval Documentation............................. 5

Task 4 - Balance of Plant (BOP) Engineering ............................................... 5

Task 5 - Process Equipment Design and Major Equipment Procurement ...... 6

Task 6 - Prepare Construction Plan ............................................................... 6

Task 7 - Procure Mercury Continuous Emission Monitor (CEM) Package and

Perform Engineering and Performance Assessment ....................................... 6

Task 8 - Mobilize Contractors ................................................................. 8

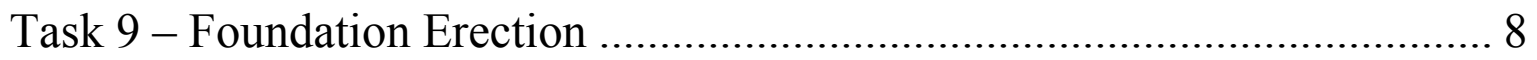

Task 17 - Carbon-Ash Management System ................................................. 8

Task 19 - Reporting, Management, Subcontracts, Technology Transfer........ 8

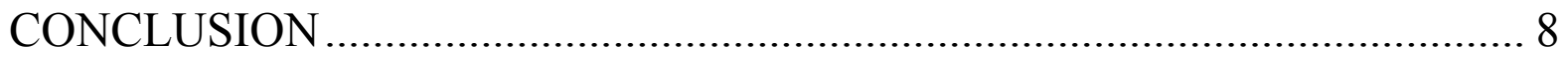

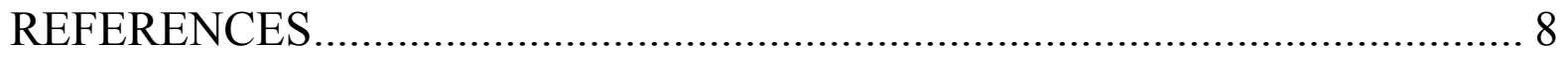

Appendix A - Statement of Project Objectives............................................ A-1

Appendix B - Performance Evaluation of Inertial Separation Probes for VaporPhase Mercury Measurements …............................................................... B-1 


\section{EXECUTIVE SUMMARY}

WE Energies Inc. (WE Energies) signed a Cooperative Agreement with the Department of Energy (DOE) in March 2003 to fully demonstrate TOXECON ${ }^{\mathrm{TM}}$ for mercury control at the WE Energies Presque Isle Power Plant. The primary goal of this project is to reduce mercury emissions from three $90 \mathrm{MW}$ units (Units 7, 8, and 9) that burn Powder River Basin (PRB) coal. Additional goals are to reduce nitrogen oxide $\left(\mathrm{NO}_{\mathrm{x}}\right)$, sulfur dioxide $\left(\mathrm{SO}_{2}\right)$, and particulate matter (PM) emissions, allow for reuse and sale of fly ash, demonstrate a reliable mercury continuous emission monitor (CEM) suitable for use in the power plant environment, and demonstrate a process to recover mercury captured in the sorbent.

WE Energies has teamed with ADA-ES Inc. (ADA-ES) and Cummins and Barnard Inc. $(\mathrm{C} \& \mathrm{~B})$ to execute this project. ADA-ES will provide engineering and management on the mercury measurement and control systems. Cummins \& Barnard will the engineer of record and will be responsible for construction, management and start-up of the TOXECON ${ }^{\mathrm{TM}}$ equipment.

This project was selected for award in January 2003. Preliminary activities covered under "Pre-Award" provision in the Cooperative Agreement began in March 2003. This first quarterly report summarizes progress made on the project in both the pre-award period, March 2003 through March 2004, and first project reporting quarter, April through June 2004. During these reporting periods, activities in Tasks 1,2, and 3 were completed and progress is being made in Tasks 4, 5, 6, 7, 8, 17 and 19 . 


\section{INTRODUCTION}

DOE awarded Cooperative Agreement No. DE-FC26-04NT41766 to WE Energies to demonstrate TOXECON ${ }^{\mathrm{TM}}$ for mercury and multi-pollutant control, a reliable mercury continuous emission monitor (CEM), and a process to recover mercury captured in the sorbent. Under this contract, WE Energies is working in partnership with the DOE.

Quarterly reports will provide project progress, results from technology demonstrations and technology transfer information.

\section{Project Objectives}

The specific objectives of this project are to demonstrate the operation of the TOXECON multi-pollutant control system and accessories and achieve:

- $90 \%$ mercury removal from flue gas through activated carbon injection,

- evaluate the potential for $70 \% \mathrm{SO}_{2}$ control and trim control of $\mathrm{NO}_{\mathrm{x}}$ from flue gas through sodium-based or other novel sorbent injection,

- reduced PM emissions through collection by the TOXECON baghouse,

- recovery of $90 \%$ of the mercury captured in the sorbent,

- $100 \%$ of fly ash collected in the existing electrostatic precipitators be available for utilization,

- demonstration of a reliable, accurate mercury CEM suitable for use in the power plant environment,

- successful system integration and optimization of TOXECON operation for mercury and multi-pollutant control.

\section{Scope of Project}

The TOXECON Retrofit for Mercury and Multi-Pollutant Control on Three 90 MW CoalFired Boilers Project will be completed in two Budget Periods. These two Budget Periods are:

Budget Period 1: Project Definition, Design \& Engineering, Prototype Testing, Major Equipment Procurement, and Foundation Installation.

Budget Period 2: CEM Demonstration, TOXECON Erection, TOXECON Operation, and Carbon Ash Management Demonstration

As indicated by the title, Budget Period 1 will initiate the project with project definition activities including NEPA, followed by design, which includes specification and procurement of long lead-time major equipment, and installation of foundations. In addition, testing of prototype mercury CEM and sorbent regeneration processes will be conducted. 
Following in Budget Period 2, the TOXECON system will be constructed and operated. Operation will include optimization for mercury control, parametric testing for $\mathrm{SO}_{2}$ and $\mathrm{NO}_{\mathrm{x}}$ control, and long term testing for $\mathrm{SO}_{2}$ and $\mathrm{NO}_{\mathrm{X}}$ control. The mercury CEM and sorbent regeneration processes will be demonstrated in conjunction with the TOXECON system operation.

Each task is described in the Statement of Project Objectives (SOPO) that is part of the Cooperative Agreement. For reference in this and future quarterly reports, the original SOPO for this project can be found in Appendix A.

\section{EXPERIMENTAL}

None to report.

\section{RESULTS AND DISCUSSION}

A pre-award kickoff meeting was held in Pittsburgh in February 2003. At this meeting, a Milestone Schedule with tasks that needed to be completed prior to contract award was distributed. An example of this schedule can be seen below. A project conference call meeting was held on each Wednesday from March until September 2003, when all of the tasks were completed. Meeting notes provide the best documentation of activities during this period. These notes can be found in Appendix B.

Between October 2003 and March 2004, when the Cooperative Agreement was signed, minimal work was performed on the project, with the exception of activities on Task 7 described below.

After the contract was awarded in March 2004, all activities fell under one of nineteen tasks outlined in the SOPO. This report updates the status and activities conducted in each of the tasks in Budget Period 1. 
MILESTONE SCHEDULE CCPI ( WE Energies)

\begin{tabular}{|c|c|c|c|c|c|c|c|c|c|c|c|c|}
\hline 'roject Manager: & & & & & & & & & \multicolumn{4}{|c|}{ Last Modified: $02 / 18 / 03$} \\
\hline $\begin{array}{l}\text { PARTICIPANT } \\
\text { Activities }\end{array}$ & Jan & Feb & Mar & Apr & May & Jun & Jul & Aug & Sep & Oct & Nov & Dec \\
\hline Technical & & 1,2 & $3,4,5$ & & & 6 & & & & & & \\
\hline Environmental & & 1 & 2,3 & & & 4 & & & & & & \\
\hline Cost & & 1,2 & 3 & 4 & 5 & & & & & & & \\
\hline $\begin{array}{l}\text { Business \& } \\
\text { Management }\end{array}$ & & $\begin{array}{c}1,2,3,4,5, \\
6,7\end{array}$ & 8,9 & 10,11 & 12 & & & & & & & 13 \\
\hline Patent \& Data & & 1 & 2,3 & & & & & & & & & \\
\hline Other & & & & & & 1,2 & $3,4,5$ & 6 & & & & \\
\hline & Jan & Feb & Mar & Apr & May & Jun & Jul & Aug & Sep & Oct & Nov & Dec \\
\hline $\begin{array}{l}\text { DOE/NETL } \\
\text { Activities }\end{array}$ & 1 & $\begin{array}{c}2,3,4,5, \\
6,7,8,9, \\
10,11, \\
12,13,14\end{array}$ & $\begin{array}{c}15,16 \\
17\end{array}$ & 18,19 & $\begin{array}{l}20,21, \\
22,23\end{array}$ & $\begin{array}{c}24,25 \\
26\end{array}$ & 27,28 & & & & & \\
\hline
\end{tabular}

\section{PARTICIPANTS ACTIVITIES}

\section{TECHNICAL}

1. Identify Project Team

2. Respond to NETL's Fact

Finding Letter

3. Complete Statement of Work

4. Confirm Site Suitability

and Availability

5. Resolve all Technical Issues

6. Complete Site Agreements and Submit to NETL

$02 / 14 / 03$

$03 / 05 / 03$

$03 / 14 / 03$

$03 / 31 / 03$

$03 / 31 / 03$

$06 / 02 / 03$

ENVIRONMENTAL

Respond to NETL's Fact

Finding Letter

2. Identify Environmental Issues

3. Determine NEPA Plan

4. Submit Environmental Information Volume (Final)

\section{COST}

1. Submit Pre-Award Cost with Description and Detai

2. Respond to NETL's Fact Finding Letter

3. Address Audit Issues

4. Resolve All Cost Proposal

$$
\text { Issues }
$$

5. Confirm Cost Reasonableness

$\mathrm{N} / \mathrm{A}$

$03 / 07 / 03$

$03 / 14 / 03$

06/30/03

$02 / 26 / 03$

03/05/03

$03 / 31 / 03$

$04 / 07 / 03$

$05 / 15 / 03$

\section{BUSINESS AND MANAGEMENT}

1. Issue Draft Milestone Schedule

2. Confirm Exceptions and Deviations

3. NETL/Participant Agree to

Milestone Schedule

4. NETL/Participant Agree to Preaward Work Plan

5. Issue Revised Management Plan

6. Issue Updated Funding Plan

7. Issue Draft Repayment Plan

8. Respond to NETL's Fact Finding Letter

9. Confirm Teaming Arrangements

10. Achieve Funding for Project Definition Phase, First Budget Period

Issues

12. Provide Negotiated Major Subcontract Documents

13. Commit Financing for Remainder of the Project end by $1^{\text {st }}$ Budget Period

\section{Identify Patent Data Issu}

2. Request Patent Waiver

3. Resolve all Patent and Data

\section{DOE/NETL Activities}

1. Project Assigned to Project Manage

2. Preaward Meeting

3. Request Preaward Cost

4. Request Milestone Schedule

5. Identify Project Teams

6. Issue Sample Preaward Milestone Schedule

7. Review Proposals for Fact Finding

8. Review Preaward Work Plan and

Cost and Issue Anticipatory Letter

9. Agree to Milestone Schedule

10. Request Audit

11. Issue Sample Repayment Plan

12. NETL Issues Fact Finding Letter

3. Review Revised Management Plan

14. Review Revised Financing Plan

15. Review First Draft of Repayment Plan

16. Complete Technical Evaluation of Cost
17. Review Revised Statement of Work

18. Prepare Negotiation Memo

19. Submit Negotiation Memo for Approval

20. Receive Approval of Negotiation Memo

21. Approved Repayment, Financing, Mgmt. Plan, Communication Plan \& SOW

22. Issue Patent Waivers

23. Complete Negotiation

24. Update Negotiation Memo

25. Submit Negotiation Memo \& Cooperative Agreement (CA) to CCPI Product Team 26. Submit Negotiation Memo \& CA to HQ

27. Receive Approval of Negotiation Memo \& CA 28. Participant Signs CA

$01 / 28 / 03$ $02 / 05 / 03$

$02 / 05 / 03$

$2 / 05 / 03$

$2 / 05 / 03$

$02 / 05 / 03$

$02 / 05 / 03$

$02 / 14 / 03$

$02 / 14 / 03$

$02 / 14 / 03$

$02 / 05 / 03$

$02 / 07 / 03$

$02 / 07 / 03$

$02 / 21 / 03$

$02 / 28 / 03$

$03 / 14 / 03$

$03 / 21 / 03$

$03 / 28 / 03$

$04 / 04 / 03$

$04 / 18 / 03$

$05 / 16 / 03$

$05 / 16 / 03$ $05 / 30 / 03$

$05 / 30 / 03$

$6 / 06 / 03$

$06 / 13 / 03$ $6 / 27 / 03$ $06 / 27 / 03$ $07 / 15 / 03$ 03/30/03

04/30/03

$04 / 30 / 03$

$05 / 16 / 03$

$12 / 31 / 03$

\section{PARTICIPANT ACTIVITIES (continued)}

\section{OTHER}

1. Complete Foundation Design

2. Prepare Bid Package

$03 / 05 / 03$

3. Go Out for Bids

4. Receive Bids

6. Award Foundation Contract
$06 / 30 / 03$

$07 / 07 / 03$

$07 / 21 / 03$

$07 / 28 / 03$

$08 / 04 / 03$ 


\section{Task 1 - Design Review Meeting}

A design review meetings was held on June 21 and 22, 2004 at Cummins \& Barnard's office in Ann Arbor, Michigan to discuss the project, system hardware components, costs, and schedules. The meeting was attended by WE Energies, DOE, EPRI, ADA-ES, Cummins \& Barnard and CaTS (Cummins \& Barnard's construction). This task is complete.

\section{Task 2 - Project Management Plan}

An updated Project Management Plan was prepared and submitted to DOE on July 23, 2004. This Management Plan was updated based on information provided at the Design Review Meeting held under Task 1. The plan will be suitable for use in tracking project progress at the task level using the earned value management system and will include the following information. The Management Plan includes:

- Final Work Breakdown Structure;

- Final Statement of Project Objectives;

- Schedule Baseline;

- Cost Baseline;

- Technology Baseline; and

- Management Controls.

This task is complete.

\section{Task 3 - Provide NEPA Documentation, Environmental Approvals Documentation and Regulatory Approval Documentation}

An Environmental Assessment was prepared in compliance with the National Environmental Policy Act (NEPA) and submitted to DOE. DOE issued a Finding of No Significant Impact for this project in September 2003. This document can be obtained or question answered by contacting Mr. Lloyd Lorenzi, NEPA Compliance Officer, U.S. DOE/NETL, at lorenzi@netl.doe.gov.

This task is complete.

\section{Task 4 - Balance of Plant (BOP) Engineering}

The following activities were conducted on this task:

- Preparation and issuance of the specification for the Baghouse procurement package.

- Development of Preliminary General Arrangements

- Ductwork and support steel design

- Preparation and issuance of the Damper specification

- Preparation and issuance of the specification for the ash silo and ash handling systems 
- Preparation and issuance of the specification for the booster fans

- Preparation of preliminary P\&ID's

- Electrical Systems Load study

\section{Task 5 - Process Equipment Design and Major Equipment Procurement}

The following major equipment packages were in the procurement stage during this reporting period:

- Baghouse package was sent out for bid, four bidders responded and a detailed evaluation resulted in a baghouse vendor being selected. A limited notice to proceed was authorized by WE Energies on June 23, 2004.

- Ductwork dampers package was sent out for bids, four bidders responded and a detailed evaluation is currently underway to select the vendor.

\section{Task 6 - Prepare Construction Plan}

Work on the construction plan and reports are currently underway. A detailed schedule has been developed along with a budget monitoring report to track construction progress.

\section{Task 7 - Procure Mercury Continuous Emission Monitor (CEM) Package and Perform Engineering and Performance Assessment}

Activities under Task 7 will be performed in both Budget Periods 1 and 2. The overall goal of this task in Budget Period 1 is to survey existing components for availability and suitability for integration into a mercury Continuous Emission Monitoring (CEM) system. The major components of a mercury CEM are:

1. Extraction Probe - consists of stinger, inertial filter, capability for dilution, temperature and flow control

2. Converter - converts oxidized mercury to elemental mercury

3. Analyzer - measures elemental mercury

4. Calibrator - elemental mercury generator

Work on this task began in June 2003. The first evaluations were conducted at WE Energies Pleasant Prairie Power Plant in July and August 2003 on extraction probes and calibrators. Three different probes and two different calibrators were tested. This work was summarized in a paper that was presented at the Air Quality IV Conference in September 2004. The paper can be found in Appendix B.

ADA-ES designed and built several prototype analyzers that are used in all of our field evaluations. The measurement technology used in the ADA-ES analyzer is gold amalgamation-cold vapor atomic adsorption. Many of the commercially available analyzers 
use gold amalgamation to concentrate the mercury and either atomic adsorption or atomic fluorescence to measure the desorbed mercury. After experiencing gold fouling at many sites, especially at sites with high sulfur bituminous coals, evaluating existing technologies and talking to many of the suppliers, ADA-ES decided to move away from gold amalgamation instruments and pursue other technologies. Thermo Electron (Thermo) offered the most interesting option with a direct mercury measurement using atomic fluorescence. Thermo, who is the leading supplier of measurement instruments to the utility industry, also had a shelf full of technologies that they had earmarked for their new mercury analyzer. To expedite the integration of the components and to assure that a CEM would be ready by summer of 2005, ADA-ES teamed with Thermo to perform the field evaluation of its components. After January 2004, component evaluations were conducted exclusively on Thermo supplied components.

Since January 2004 testing has been conducted at six different sites, three bituminous sites (low, medium and high sulfur bituminous coals) and three PRB sites. The commercialization process has three distinct stages that are described below:

1. Prototype - first time in the field

2. Alpha - field tested, but still requires development on major issues (current research grade)

3. Beta - most of the bugs have been worked out, but still troubleshooting and conducting long term testing for commercial applicability

A comparison of mercury measurements made using a Thermo prototype analyzer and an ADA-ES analyzer can be seen in Figure 1.

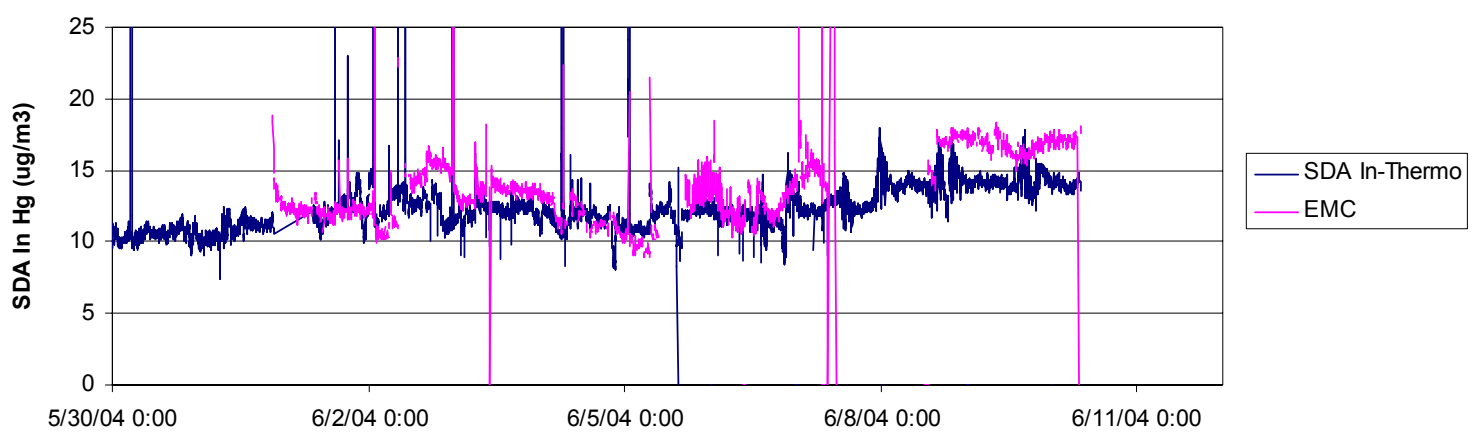

Figure 1. Mercury measurements made with two different analyzers at a site burning PRB coal. The extraction location was upstream of a spray dryer.

The team is working towards having all of the components in the beta phase by November 2004. If arrangements can be made with Presque Isle personnel, the plan is to take the beta version to Presque Isle, install it and start collecting long-term data. The target date for commercial release of the instrument is Summer 2005. 


\section{Task 8 - Mobilize Contractors}

Construction mobilization began on June 28, 2004. Full mobilization is expected to be complete by the end of July. Initial field pre-construction work will begin in July with the demolition and relocation of an existing parking lot away from the construction site. Major subcontractor mobilizations will continue through August, 2004.

\section{Task 9 - Foundation Erection}

No construction work was scheduled during this period. Initial foundation construction is expected in early September.

\section{Task 17 - Carbon-Ash Management System}

The goal of this task is to evaluate the viability of integrating existing technologies into a system that would recover mercury from the ash/sorbent mixture collected in the fabric filter.

A preliminary survey of available technologies was conducted.

\section{Task 19 - Reporting, Management, Subcontracts, Technology Transfer}

Under this tasks reports, as required in the Financial Assistance Reporting Requirements Checklist and this Statement of Project Objectives, are prepared and submitted. Nonproprietary technical progress reports are distributed among team members to keep the team informed on the project status. Subcontract management, communications, outreach, and technology transfer functions are also performed under this task.

\section{CONCLUSION}

This is the first Technical Progress Report under Cooperative Agreement No. DE-FC2604NT41766. Work has started in TOXECON system design and engineering. Work was also started in evaluating components for a mercury continuous emissions monitor system.

\section{REFERENCES}

None this reporting period. 


\section{Appendix A - Statement of Project Objectives}




\section{$\underline{\text { Attachment A - Statement of Project Objectives }}$}

The primary goal of this project is to reduce mercury emissions from three $90 \mathrm{MW}$ units at the We Energies Presque Isle Power Plant. Additional goals are to reduce nitrogen oxide $\left(\mathrm{NO}_{\mathrm{x}}\right)$, sulfur dioxide $\left(\mathrm{SO}_{2}\right)$, and particulate matter $(\mathrm{PM})$ emissions, allow for reuse and sale of fly ash, develop and demonstrate a reliable mercury continuous emission monitor (CEM) suitable for use in the power plant environment, and demonstrate a process to recover mercury captured in the sorbent. To achieve these goals, We Energies (the Participant) will design, install, and operate a TOXECON ${ }^{\mathrm{TM}}$ (TOXECON) system designed to clean the combined flue gases of units 7, 8, and 9 at the Presque Isle Plant.

TOXECON is a patented process in which a fabric filter system (baghouse) installed down stream of an existing particle control device is used in conjunction with sorbent injection for removal of pollutants from combustion flue gas. The flue gas emissions will be controlled from the three units using a single baghouse. Mercury will be controlled by injection of activated carbon or other novel sorbents, while $\mathrm{NO}_{\mathrm{x}}$ and $\mathrm{SO}_{2}$ will be controlled by injection of sodium based or other novel sorbents. Addition of the TOXECON baghouse will provide enhanced PM control. Sorbents will be injected downstream of the existing particle collection device to allow for sale and reuse of captured fly ash, uncontaminated by activated carbon or sodium sorbents.

Methods for sorbent regeneration, i.e. mercury recovery from the sorbent, will be explored and evaluated. Components available for use will be evaluated and the best available will be integrated into a mercury CEM suitable for use in the power plant environment. This demonstration will provide for the use of a novel multi-pollutant control system to reduce emissions of mercury and other air pollutants, while minimizing waste, from a coal-fired power generation system.

\section{A. Project Objectives}

The specific objectives of this project are to demonstrate the operation of the TOXECON multi-pollutant control system and achieve:

- $90 \%$ mercury removal from flue gas through activated carbon injection,

- evaluate the potential for $70 \% \mathrm{SO}_{2}$ control and trim control of $\mathrm{NO}_{\mathrm{x}}$ from flue gas through sodium-based or other novel sorbent injection,

- reduced PM emission through collection by the TOXECON baghouse,

- recovery of $90 \%$ of the mercury captured in the sorbent,

- $100 \%$ of fly ash collected in the existing electrostatic precipitator available for utilization,

- demonstration of a reliable, accurate mercury CEM suitable for use in the power plant environment,

- $\quad$ successful system integration and optimization of TOXECON operation for mercury and multi-pollutant control. 
The participant will design and construct a TOXECON multi-pollutant control system as a retrofit to three $90 \mathrm{MW}$ coal-fired boilers at the Presque Isle Power Plant. The objectives will be achieved through injection of various sorbents into the flue gas stream to capture mercury, $\mathrm{SO}_{2}, \mathrm{NO}_{\mathrm{x}}$, and other air toxics as appropriate. Efforts will be focused on development and demonstration of two ancillary technologies, a mercury continuous emission monitor and a method of treating the captured activated carbon sorbent for regeneration or for reuse in the system rather than disposal. The demonstration project will provide the utility industry a benchmark for cost and performance of a commercial scale mercury control systems for application on coal-fired power generation systems.

\section{B. Scope of Project}

The TOXECON Retrofit for Mercury and Multi-Pollutant Control on Three 90 MW CoalFired Boilers Project will be completed in two Budget Periods. These two Budget Periods are:

Budget Period 1: Project Definition, Design\& Engineering, Prototype Development, Major Equipment Procurement, and Foundation Installation.

Budget Period 2: CEM Demonstration, TOXECON Erection, TOXECON Operation, and Carbon Ash Management Demonstration

As indicated by the title, Budget Period 1 will initiate the project with project definition activities including NEPA, followed by design, which includes specification and procurement of long lead-time major equipment, and installation of foundations. In addition, prototype development for mercury CEM and sorbent regeneration processes will be conducted.

Following in Budget Period 2, the TOXECON system will be constructed and operated. Operation will include optimization for mercury control, parametric testing for $\mathrm{SO}_{2}$ and $\mathrm{NO}_{\mathrm{x}}$ control, and long term testing for $\mathrm{SO}_{2}$ and $\mathrm{NO}_{\mathrm{x}}$ control. The mercury CEM and sorbent regeneration processes will be demonstrated in conjunction with the TOXECON system operation.

\section{Tasks to be Performed (The Participant will work directly with the company identified in the parentheses)}

\section{Budget Period I: Project Definition, Design\& Engineering, Prototype Development, Major Equipment Procurement, Foundation Installation, and Management \& Reporting.}

Task 1 - Design Review Meeting (ADA-ES) 
The project team will hold a kickoff, design review meeting including the participant, the DOE Contracting Officer's Representative (COR), major subcontractors, and other project team members as appropriate to discuss the project, system hardware components, costs, and schedules. This meeting will take place within sixty days after award with the primary purpose of providing a status of the ongoing work, specifying system requirements and planning future project activities.

\section{Task 2 - Project Management Plan (ADA-ES)}

An updated Project Management Plan will be prepared as a deliverable within 30 days following the Design Review Meeting. This plan will be updated based on information provided at the Design Review Meeting held under Task 1. The plan will be suitable for use in tracking project progress at the task level using the earned value management system and will include the following information.

- $\quad$ Final Work Breakdown Structure. A final Work Breakdown Structure will be prepared that identifies Tasks and Subtasks to be performed under the project.

- Final Statement of Project Objectives. A final Statement of Project Objectives will be prepared that describes the work to be performed under the project at the Task and Subtask level of detail, following the format of the Work Breakdown Structure.

- $\quad$ Schedule Baseline. A Schedule Baseline will be prepared in Gantt Chart format that shows the project schedule for the entire project at the Task level of detail, including major milestones and decision points. The Schedule Baseline will follow the Task structure of the Work Breakdown Structure.

- $\quad$ Cost Baseline. A Cost Baseline will be prepared showing projected monthly total project cost as a function of Task, following the format of the Work Breakdown Structure.

- Technology Baseline. A description of the Baseline Technology will be prepared, including a summary of technology experience and applications, design issues to address as identified in the Design Review Meeting, mass balances, and identification of major equipment.

- $\quad$ Management Controls. An updated listing of key organizations and individuals involved with the project, functions and authorities of each, lines of authority, procedures used to control cost expenditures, and technical decision making procedures.

Task 3 -Provide NEPA Documentation, Environmental Approvals Documentation and Regulatory Approval Documentation (ADA-ES)

The Participant will provide a completed Environmental Information Volume and other information to DOE and any DOE authorized subcontractors necessary to allow completion of the Environmental Assessment required for compliance with the National Environmental Policy Act (NEPA). The Participant will provide documentation to DOE demonstrating that 
the participant has the necessary approvals from appropriate environmental regulatory bodies to proceed with the project. The Participant will provide any rulings received from state public utilities commissions regarding this project to DOE.

Task 4 - Balance of Plant (BOP) Engineering (C\&B)

In addition to the major process equipment, ductwork and distributed control systems (DCS) described herein, a substantial balance of plant engineering and design effort is required. The Participant will provide BOP engineering and design necessary for the construction, installation, and operation of the TOXECON technology. The Participant will subject the BOP design to standard engineering review and acceptance procedures. The BOP engineering and design scope includes the following items.

- Demolition, excavation, underground utility relocation design.

- Baghouse arrangement and plant equipment general arrangement design.

- Foundation design.

- Civil, structural and ductwork design.

- Baghouse and building enclosure design.

- Mechanical design, including fans, ductwork, dampers, sorbent handling silo, and air compressors.

- Electrical system study, motor control center (MCC) and electrical design.

- Plant controls and instrumentation design and CEM design.

- Piping and instrumentation diagrams, and piping design for carbon, water, air, sorbent/ash, and flue gas subsystems.

- Water injection skid system design.

- Carbon injection skid systems design.

For each BOP design item the participant will provide a definition of design scope, appropriate drawings, specifications, and instructions sufficient for the construction, installation, and operation of TOXECON system. The participant will subject the BOP design to standard engineering review and acceptance procedures.

Task 5 - Process Equipment Design and Major Equipment Procurement (C\&B)

The Participant will provide expertise in the development of the final design and specifications for the TOXECON technology. Major equipment bid packages will be prepared and awarded in this task.

\section{Subtask 5.1 - Process Equipment Design}

The Participant will provide a design for the TOXECON system to be installed on at the Presque Isle Plant. The Participant will provide the final design and specifications for the baghouse and sorbent injection system, which are the major components that must be integrated in the TOXECON technology. The baghouse will be capable of processing the combined flue gases of Units 7, 8, and 9 at the Presque Isle Plant. The baghouse will be capable of filtering activated carbon sorbent and other sorbents used 
in the TOXECON system, and shall be sized appropriately such that sufficient sorbent can be injected to meet project pollution reduction goals as stated in Section A, Project Objectives. The sorbent injection system will be capable of injecting activated carbon and other sorbents in sufficient quantity to meet project pollution reduction goals. Performance data from ongoing, non-commercial demonstrations will be included in the design as appropriate. Flow modeling will be performed to confirm design parameters. Process instrumentation necessary to track performance will be specified.

Subtask 5.2 - Major Equipment Procurement

Formal specifications and bid packages will be prepared, negotiated and awarded as appropriate. Equipment packages include: baghouse, demolition and underground work, foundation, mechanical and steel, electrical and controls, sorbent silo and sorbent handling system, ID fans and motors, and air compressors.

\section{Task 6 - Prepare Construction Plan (C\&B)}

The Participant will develop a Construction Plan that identifies and describes all crucial activities required for an on-time completion of the design, procurement, construction, and start-up phases of the project. The Construction Plan will include a Project Plan that will specify material types and quantities, labor craft requirements, and schedules necessary for the successful construction of the TOXECON system. The Construction Plan will also include a detailed Gantt Chart that will identify design, procurement, construction, and startup activity schedules with all critical path items and milestones identified. The Construction Plan Gantt Chart will be used to coordinate activities among subcontractors, and to track progress of activities against a baseline schedule to assist in maintaining the project schedule.

Task 7 - Procure Mercury Continuous Emission Monitor (CEM) Package and Perform Engineering and Performance Assessment (ADA-ES)

Mercury CEM components will be selected and procured. The Participant will assess the suitability of commercially-available equipment to the needs of this program. The Participant will evaluate mercury CEM components and incorporate the various components into a fully functional mercury CEM capable of measuring mercury content of a coal-fired flue gas stream suitable for evaluating performance of the TOXECON system. The mercury CEM should allow for automated operation, requiring only periodic operation and maintenance by plant operating personnel. It is a goal of this program to work with suppliers to significantly improve reliability and decrease operations and maintenance requirements of currently available mercury CEM devices. Two subtasks will be performed in Budget Period 1.

Subtask 7.1 - System Design, Evaluation and Analysis (Laboratory and Field) 
The Participant will evaluate mercury CEM components including the extraction, detector, calibration, sample transport, conversion and separation, and control and data management subsystems. The participant will survey existing components for availability and suitability for integration into a mercury CEM system. The participant will perform laboratory and/or field testing as appropriate of each individual subsystem to determine its suitability based on criteria stated above. The Participant will procure suitable components for system integration testing.

\section{Subtask 7.2 - System Integration and Testing}

The participant will integrate components procured in Subtask 7.1 into an operational mercury CEM device. The Participant will perform necessary laboratory evaluations and system check out procedures to ensure proper operation and suitability prior to field evaluations. The Participant will develop written operating instructions for the mercury CEM system and an evaluation plan, including performance criteria, to assess mercury CEM system performance.

The Participant will perform a field evaluation at a coal-fired power generation facility to assess the performance of the mercury CEM against criteria established above according to the evaluation plan identified above.

\section{Task 8 - Mobilize Contractors (C\&B)}

The Participant will mobilize contractors based on the project schedule in accordance the Construction Plan developed under Task 6. These include construction management, demolition and excavation, mechanical, electrical, and foundation contractors. Mobilization is the first step in granting authorization for contractors to initiate work. Mobilization includes installing temporary construction infrastructure required before crews arrive on site, hiring personnel and subcontractors, and developing a utilization plan for large equipment including cranes.

\section{Task 9 - Foundation Erection (C\&B)}

After all required demolition work, relocation of below grade equipment, and earthwork has been completed; foundations for all major equipment will be installed. Work will be performed in accordance with design specifications developed under Tasks 4 and 5, and in accordance with the Completion Plan developed in Task 6.

The existing paved parking lot and other existing structures as required will be demolished and scrap material will be disposed of in an appropriate manner. Excavation will be performed to expose below grade equipment and utilities, including, storm pipe, trench drains, fire suppression water, and water as appropriate. These utilities will be relocated to allow for installation of the TOXECON system. New below grade utilities required for installation and operation of the TOXECON will be installed. General excavation will be performed to prepare for construction of foundations for all major pieces of equipment. Concrete foundations will be installed for the baghouse, sorbent injection equipment, water 
injection skids, and other equipment as required for the installation and construction of the TOXECON system. Roads disturbed during foundation erection will be restored, suitable for supporting access to plant operations. Large equipment will be deployed as required by the Large Equipment Deployment Plan developed in Task 8.

Task 17 - Carbon-Ash Management System (ADA-ES)

Subtask 17.1 - Evaluate Options and Pilot Test Carbon-Ash Management System

The Participant will evaluate the viability of a mercury recovery system for the purpose of recovering mercury from the sorbent/ash mixture and allowing for beneficial reuse of this product. The Participant will also evaluate the processed sorbent for potential reuse. This may also allow the sorbent to be recycled in the TOXECON system. Activities to be performed under this budget period will include the following. The Participant will perform a survey to identify potential technology options. From these options, a technology will be chosen for further study. The Participant will evaluate the viability of the system and approach through engineering analysis and laboratory and/or pilot scale testing.

Task 19 - Reporting, Management, Subcontracts, Technology Transfer (ADA-ES)

The Participant will employ standard project management techniques for the purpose of keeping all activities on schedule and within the budget. Activities performed under this task will be used to provide oversight and control throughout execution of the project during Budget Period 1. The Participant will hold team meetings with attendance required from the organizations most involved during the active phase of the project to facilitate communication and enable the appropriate technical input into all activities.

The Participant will prepare and submit reports as required in the Financial Assistance Reporting Requirements Checklist and this Statement of Project Objectives. The Participant will report data such that earned value management techniques can be used to evaluate progress of Tasks under Budget Period 1. Non-proprietary technical progress reports will be distributed among team members to keep the team informed on the project status. Subcontract management, communications, outreach, and technology transfer functions will also be performed under this task.

Budget Period II: CEM Demonstration, TOXECON Erection, TOXECON Operation, Carbon Ash Management Demonstration, and Management \& Reporting.

Task 7 - Procure Mercury CEM Package and Perform Engineering and Performance Assessment (ADA-ES)

Subtask 7.3 - Mercury CEM Design, Component Integration, and Field Testing

Efforts to develop a Mercury CEM will continue in Budget Period 2. Tasks in this period will focus on integrating components, field testing, and final design issues that 
have not been addressed in Subtask 7.2. Based on testing performed in Budget Period 1 , overall system performance and performance of individual system components will be evaluated. Redesign of the system and individual components will be performed as required. Appropriate modifications, including acquisition and integration of new components will be made to the prototype device to address system deficiencies. Further laboratory evaluations, system check out, and field evaluations will be performed as required. The prototype monitor will be installed on the TOXECON system.

Task 10 - Erect Structural Steel, Baghouse and Ductwork (C\&B)

The Participant will construct and install structural steel, ductwork, a sorbent injection system and a baghouse necessary for the operation of the TOXECON mercury removal and multi-pollutant control system. The Participant will construct and install equipment specified and procured in Task 5 in accordance with designs developed in Tasks 4 and 5. Activities will be performed in accordance with the Completion Plan developed in Task 6.

The Participant will install structural steel necessary to support the multi-level duct arrangement, baghouse, induced draft fan enclosure, access and instrumentation supports, sorbent silo, and all other equipment necessary for operation of the TOXECON system.

Stiffened plate steel ductwork will be installed that allows flue gas from Presque Isle Units 7, 8 , and 9 to enter the TOXECON baghouse or exit directly to the existing stack. Ductwork will also be installed to carry flue gas from the TOXECON baghouse, which will transition from a single duct into three, each with an induced draft fan, to carry flue gas to existing independent outlet ducts for Units 7, 8, and 9.

The Participant will install a baghouse to filter the combined flue gas streams of Units 7, 8, and 9 at the Presque Isle Plant. The baghouse shall be capable of filtering activated carbon sorbent and other sorbents used in the TOXECON system, and shall be sized appropriately such that sufficient sorbent can be injected to meet project pollution reduction goals as stated in Section A, Project Objectives.

The Participant will install steel platforms to serve as working surfaces allowing performance of standard maintenance on equipment and access to test ports and probes. These areas include access inside the existing powerhouse to the exhaust duct water injection ports, if required, and access to baghouse inlet duct and outlet duct.

Task 11 - Balance of Plant Mechanical and Civil/Structural Installations (C\&B)

The Participant will construct and install mechanical balance of plant equipment necessary for operation of the TOXECON system according to designs developed in Task 4 and 5, including equipment specified and procured under Task 5 . Activities will be performed in accordance with the Completion Plan developed in Task 6 . Balance of plant mechanical installations will include the following: 
- Baghouse and duct insulation and lagging

- Hopper, fan, and silo enclosures and siding

- Sorbent/Ash vacuum exhauster skids and enclosure

- Piping, valves, support, and accessories

- Sorbent/Ash silo and unloading equipment

- Induced draft fans

- Instrument air and controls system

- Carbon injection system

- Unit tie-ins

- Heating, ventilation, air conditioning, fire protection, and support systems

- Water injection system

- Miscellaneous guard post and guardrails

Task 12 - Balance of Plant Electrical Installations (C\&B)

The Participant will install balance of plant electrical equipment necessary for operation of the TOXECON system according to designs developed in Task 4 and 5, including equipment specified and procured under Task 5. Activities will be performed in accordance with the Completion Plan developed in Task 6. Balance of plant electrical installations will include the following:

- Baghouse Power Supply

- Three MCC's

- ID Fan Power Supply

- Auxiliary Electrical Supply

- Baghouse Control Cable

- ID Fan Control Cable

- Auxiliary Equipment Control Cable

- CEMS System

- DCS System

- Freeze Protection System

- Lighting system

Task 13 - Equipment Pre-Operational Testing (C\&B)

Prior to start-up of TOXECON, each major and minor piece of equipment will be powered up and tested to assure that operation meets performance specifications. This includes all fans, blowers, compressors, support instrumentation, control systems, valves, dampers, and plant tie-ins. Pre-operation testing will include:

- ID Fan startup and checkout

- Baghouse systems startup and checkout

- Air compressor checkout

- Carbon injection system checkout 
- Sorbent/Ash handling system checkout

- Water Injection system checkout

- Instrument and controls systems checkout

- DCS programming checkout

- CEMS system checkout

- Electrical systems checkout

Task 14 - Start Up and Operator Training (C\&B)

The Participant will devote sufficient time to allow for successful start up and debugging of full system operation. The Participant will conduct operator training during the start-up period. The Participant will develop operating manuals and distribute copies to operating personnel sufficient for training and operation of the TOXECON system. Training will take place in several forms including classroom sessions for all pertinent personnel.

Task 15 - Operate, Test, Data Analysis and Optimize TOXECON for Mercury Control (ADA-ES)

\section{Subtask 15.1 - Test Plan Development}

The Participant will develop Test Plans for each major area of investigation. The Participant will develop Test Plans with input from team members as appropriate, and will be subject to review by team members prior to submission to DOE for comment. The Participant will develop test plans for evaluating and optimizing the TOXECON technology including:

- TOXECON Evaluation

- Mercury Recovery

- Mercury CEM

The Participant shall submit a Draft Copy of each Test Plan to the DOE COR for review. The COR shall review each Test Plan and provide comments to the Participant within 30 days of receipt. The Participant shall address comments made by the DOE COR and submit a Final copy of each Test Plan to the DOE COR for approval. The COR will provide approval of each Final Test Plan that fully addresses COR comments within 30 days of receipt. The Participant shall not initiate testing prior to completion of the Test Plan approval process.

TOXECON Evaluation Test Plan. The Participant will develop a Test Plan to evaluate mercury and multi-pollutant control through sorbent injection and a plan to optimize TOXECON operation for maximum mercury and multi-pollutant removal under varying operating conditions. The Test Plan will address the following issues: 
- A plan for start-up, optimization, long-term performance monitoring and acceptance testing of TOXECON for mercury control under varying operating conditions. Operating strategies for optimizing mercury control including but not limited to temperature control will be addressed.

- A plan and schedule for monitoring mercury entering TOXECON and mercury emissions, including demonstrating integrated operation of all subsystems and components. A plan and schedule for periodic manual stack measurements of both particulate matter and mercury. A plan and schedule for measurement of $\mathrm{NO}_{\mathrm{x}}$ and $\mathrm{SO}_{2}$ emission reduction.

- Sorbents and suppliers of sorbents for mercury, $\mathrm{NO}_{\mathrm{x}}$ and $\mathrm{SO}_{2}$ removal will be identified.

- A plan for evaluating fabric filter bags selected for use to determine their suitability for continued testing. Bag integrity through periodic bag strength testing, and measurement of as-received, vacuumed, and in situ bag permeability will be conducted.

- Operating data to be tracked including but not limited to temperature, pressure drop, cleaning frequency, sorbent injection rate, and opacity will be identified.

- A plan for short-term, parametric tests to evaluate alternate activated carbon sorbents and operating strategies.

- A plan for evaluating and optimizing the control of $\mathrm{SO}_{2}$ and $\mathrm{NO}_{\mathrm{x}}$ through sorbent injection under varying operating conditions. A plan for investigating waste disposal and mercury recovery from these sorbents

Mercury Recovery Test Plan. The Participant will develop a Test Plan to evaluate performance of the mercury recovery system developed under Task 17. The Participant will fully evaluate the ability of the chosen system to recover mercury from spent activated carbon sorbent and the feasibility of reuse of the sorbent in the TOXECON system. The plan will include an evaluation of methods for disposing of the mercury captured in the mercury recovery system.

Mercury CEM Test Plan. The Participant will develop a Test Plan to evaluate the performance of the mercury CEM developed under Task 7. The CEM will be evaluated on the full scale TOXECON system. The plan will be designed to evaluate the operability and reliability of the instrument. The plan will be designed to evaluate the accuracy and reproducibility of mercury emission measurements.

\section{Subtask 15.2 - Optimize TOXECON for Mercury Control}

The Participant will operate the TOXECON system in accordance with the TOXECON Evaluation Test Plan developed under Task 15.1. The Participant will operate the TOXECON system to evaluate its performance with respect to mercury control as a function of operating variables. The Participant will evaluate the long-term performance of the TOXECON system, and the Participant will perform short term parametric testing to evaluate alternative sorbents and operating strategies. The Participant will measure mercury emission 
reductions, evaluate filter bag integrity, and track operating data to quantify TOXECON performance as a function of operating conditions.

Subtask 15.3 - Continuous Mercury Measurements

The Participant will operate the mercury CEM to evaluate the operability, reliability, accuracy, and repeatability of the mercury CEM system in accordance with the Mercury CEM Test Plan developed in Subtask 15.1. The Participant will evaluate the performance of the mercury CEM developed under Task 7 on the full scale TOXECON system. The mercury CEM will be used to evaluate the performance of the TOXECON system for its ability to control mercury emissions.

Task 16 -Operate, Test, Data Analysis and Optimize TOXECON for $\mathrm{SO}_{2}$ and NOx Control (ADA-ES)

After TOXECON operation and performance is established for mercury control, the Participant will conduct tests to assess the capability of TOXECON to control other pollutants including $\mathrm{SO}_{2}$ and NOx. Injection equipment and measurement instrumentation will be designed, procured and installed specifically for these tests. The Participant will perform evaluations in accordance with the TOXECON Evaluation Test Plan developed under Subtask 15.1. The Participant will measure $\mathrm{NO}_{\mathrm{x}}$ and $\mathrm{SO}_{2}$ emission reductions and track operating data to quantify TOXECON performance as a function of operating conditions.

Task 17 - Carbon-Ash Management System (ADA-ES)

Subtask 17.2 - Procure Full-Scale Demonstration System and Evaluate Carbon-Ash Management System

Providing results from Subtask 17.1 meet project goals, the Participant will procure a fullscale demonstration unit of the mercury recovery system for testing of the sorbent-ash mixture collected in TOXECON. The Participant will install the mercury recovery system on the TOXECON to allow for continuous removal and processing of the spent sorbent and ash mixture from the TOXECON system. The Participant will perform shakedown testing to ensure proper operation of all subsystems and the integrated system as a whole prior to incorporation into the TOXECON system. The Participant will evaluate the performance of the mercury recovery system as installed on the TOXECON system in accordance with the Mercury Recovery Test Plan developed in Subtask 15.1. The Participant will evaluate the ability of the mercury recovery system to evolve mercury from used sorbent in the presence and absence of $\mathrm{NO}_{\mathrm{x}}$ and $\mathrm{SO}_{2}$ sorbents. The Participant will evaluate the ability of the regenerated sorbent to capture mercury. The Participant will evaluate the methods for disposal of mercury captured in the mercury recovery system. Contingent on successful results, the Participant will provide an assessment of the capital and operating costs of the mercury recovery system and provide a cost/benefit analysis relative to inclusion of this system in the TOXECON system. 
Task 18 - Revise Design Specifications, Prepare O\&M Manuals (ADA-ES)

The Participant will prepare revisions to specifications based on the as-built installation and actual operating experience of the system. The Participant will prepare revised operating and maintenance manuals based on as-built installation and operating experience.

Task 19 - Reporting, Management, Subcontracts, Technology Transfer (ADA-ES)

The Participant will employ standard project management techniques for the purpose of keeping all activities on schedule and within the budget. Activities performed under this task will be used to provide oversight and control throughout execution of the project during Budget Period 2. The Participant will hold team meetings with attendance required from the organizations most involved during the active phase of the project to facilitate communication and enable the appropriate technical input into all activities.

The Participant will prepare and submit reports as required in the Financial Assistance Reporting Requirements Checklist and this Statement of Project Objectives. The Participant will report data such that earned value management techniques can be used to evaluate progress of Tasks under Budget Period 2. Non-proprietary technical progress reports will be distributed among team members to keep the team informed on the project status. Subcontract management, communications, outreach, and technology transfer functions will also be performed under this task.

D. Deliverables. In addition to the reports identified on Attachment B, the Financial Assistance Reporting Requirements Checklist, and in specific sections of this agreement, the Participant shall provide documents, reports, and briefings as identified below.

Project Management Plan. The Participant shall provide an updated Project Management Plan within 30 days of the Design Review Meeting held under Task 1.

Construction Plan. The Participant shall provide a Construction Plan developed under Task 6.

Test Plans. The Participant shall provide the following Draft Test Plans for review by the DOE COR: Draft TOXECON Evaluation Test Plan, Draft Mercury CEM Test Plan, and Draft Mercury Recovery Test Plan. The Participant shall provide the following Test Plans for DOE approval: TOXECON Evaluation Test Plan, Mercury CEM Test Plan, and Mercury Recovery Test Plan.

Topical Report. The Participant shall submit a Preliminary Public Design Report as a Topical Report for Budget Period 1. The Participant shall submit a Draft Topical Report for Budget Period 1 within 60 days of the conclusion of Budget Period 1. DOE shall review the Draft Topical Report and provide comments to the Participant within 30 days of receipt. The Participant shall address DOE comments and submit a Final Topical Report for Budget Period 1 within 30 days. 
Public Design Report. The Participant shall submit a Public Design Report, for the purpose of public use. The Public Design Report must consolidate all design and cost information for the project at the completion of construction and start up. The report must contain sufficient information to provide an overview of the project, salient design features and data, and the role of the demonstration project in commercialization planning.

E. Briefings. Briefings and Technical Presentations shall be provided as follows.

Kickoff Design Review Meeting. The Participant shall hold a kickoff, design review meeting as, described in Task 1, within sixty days after award with the primary purpose of providing a status of the ongoing work, specifying system requirements and planning future project activities.

Design Review. The Participant shall hold a design review meeting near the end of design activities during Budget Period 1 for the purpose of presenting a review of the design process and salient design features of the TOXECON System.

Final Briefing. The Participant shall provide a Final Briefing at the conclusion of the project to provide a comprehensive summary of the accomplishments and results of this project. The location of the Final Briefing shall be Morgantown, WV. 


\section{Appendix B - \\ Performance Evaluation of Inertial Separation Probes for Vapor-Phase Mercury Measurements}




\title{
PERFORMANCE EVALUATION OF INERTIAL SEPARATION PROBES FOR VAPOR-PHASE MERCURY MEASUREMENTS
}

Sharon Sjostrom (sharons@adaes.com), Gerald Amrhein (jerrya@adaes.com), Jean

Bustard (jeanb@adaes.com), Travis Starns (traviss@adaes.com)

ADA Environmental Solutions, LLC

8100 SouthPark Way, Unit B, Littleton, CO 80120

(303) 734-1727; (303) 734-0330 fax

\author{
Randy Merritt \\ Southern Research Institute \\ 2000 Ninth Avenue South \\ Birmingham, AL 35255-5305 \\ (205) 581-2381
}

Presented at:

Air Quality IV

September $22-24,2003$

Arlington, VA 


\begin{abstract}
Measuring vapor-phase mercury from coal-fired flue gas using a continuous mercury analyzer can be complicated by the presence of particulate matter. Initially, standard sampling filters were used to remove particulate matter as the sample gas was extracted from the duct. Significant variations in the measured mercury concentration were attributed to capture of vapor-phase mercury by particulate deposited on the sampling filter. In the past few years, probes designed to inertially separate the bulk of the particulate matter from a gas sample have been successfully used with mercury analyzers to minimize particulate-related sampling artifacts.
\end{abstract}

In preparation for a Clean Coal program, a performance evaluation and comparison of commercially available inertial separation probes is being conducted. Probes designed by Baldwin Environmental, EPM Environmental (Thermo Electron Corporation), and Apogee Scientific were included in the evaluation. The probes were tested to determine their potential to oxidize mercury at various operating temperatures, their ability to accurately measure elemental and oxidized mercury spikes, and the effect of activated carbon injection into the probes $(<0.15 \mathrm{sec}$ residence time $)$ at various operating temperatures. All tests were conducted in actual flue gas. This paper presents a description of each of the probes and the test results to date. 


\section{Introduction}

The U.S. Environmental Protection Agency (EPA) is required to announce mercury MACT regulations under Title III of the Clean Air Act Amendments of 1990 by December 15, 2003. In anticipation of these regulations, WE Energies and ADA Environmental Solutions (ADAES) submitted a proposal to DOE as part of the Clean Coal Power Initiative. The proposed project, which was selected for award, is to design, install, evaluate and operate the TOXECON $^{\mathrm{TM}}$ technology for integrated emission control of mercury and particulate matter. The system will be designed to treat the gas from WE Energies Presque Isle Units 7-9. In addition to the goal of achieving $90 \%$ continuous mercury removal using powdered activated carbon injection (PAC), one of the demonstration goals is to develop and demonstrate a mercury continuous emission monitor (CEM).

There are several key components to a robust and reliable mercury CEM. These include systems to extract, pretreat, transport, and measure mercury in flue gas. Some of these components, specifically the measurement system, are commercially available and operate fairly well in some gas matrices. However, other components, such as the pretreatment system, are still in development and have not been proven on a variety of flue gas streams.

During the evaluation program described in this paper, three commercially available extraction probes were evaluated at WE Energies Pleasant Prairie Power Plant. All three probes utilize inertial separation to separate flue gas from particulate. Apogee Scientific, Baldwin Environmental, and Thermo Electron Corporation provided the probes. ADA-ES contracted with Southern Research Institute to provide the mercury analyzer and the elemental mercury spiking system. A system for spiking oxidized mercury was provided by EPA's NRML/APPC.

In general, all three probes demonstrated reliable performance in delivering a mercury-laden sample for total vapor-phase mercury measurements. This paper describes the equipment used for the evaluation, the test protocol, and the results. 


\section{Equipment Descriptions Inertial Separation Probes}

Fly ash and other particulate, such as injected sorbents, can capture or convert vapor-phase mercury if present on a sampling filter upstream of a mercury measurement system. Inertial separation probes provide a method of separating particulate from the gas sample while minimizing gas-particle interactions.

Three commercially available inertial separation probes were evaluated in a short test program. Table 1 identifies the probe manufacturers and key characteristics. Figure 1 shows photographs of each of the three probes. Another probe supplier, Mott Corporation in Farmington, Connecticut, was not included in the evaluation program because they do not provide heated systems.

Table 1. Inertial Probes Included in Evaluation Program.

\begin{tabular}{|l|l|l|l|l|}
\hline Manufacturer & Material & $\begin{array}{l}\text { Filter } \\
\text { Diameter } \\
\text { (inches) }\end{array}$ & $\begin{array}{l}\text { Design Flow } \\
\text { Rate } \\
\mathbf{a c f m})\end{array}$ & Other \\
\hline $\begin{array}{l}\text { Apogee } \\
\text { Scientific }\end{array}$ & Stainless Steel & $5 / 8$ & $10-12$ & Venturi flow meter \\
\hline $\begin{array}{l}\text { Baldwin } \\
\text { Environmental }\end{array}$ & $\begin{array}{l}\text { Stainless Steel } \\
\text { with Durinert } \\
\text { Coating }\end{array}$ & $5 / 8$ & $6-10.5$ & $\begin{array}{l}\text { Venturi flow meter } \\
\text { Heated eductor air }\end{array}$ \\
\hline $\begin{array}{l}\text { Thermo } \\
\text { Electron } \\
\text { (EPM) }\end{array}$ & Stainless Steel & $1 / 4$ & $1.5-2$ & $\begin{array}{l}\text { Heated filter blowback } \\
\text { option, dilution probe } \\
\text { option }\end{array}$ \\
\hline
\end{tabular}

The filter element in the inertial separation probe is a sintered stainless steel porous tube. A filter housing tube surrounds the filter element, creating a minimum-volume annular volume for sample collection. A high velocity gas flow is developed axially through the porous tube using a vacuum eductor installed downstream of the filter element. The sample gas is drawn radially through the porous tube at a very low face velocity, passing through the housing annulus and into the sample port. The high velocity axial gas flow separates the bulk of the particulate matter from the sample stream. Any remaining fine particles are filtered through the porous tube. The inner surface of the porous tube is self-cleaning by the scouring effect of the particles in the main gas stream. A sketch of an inertial filter is shown in Figure 2.

Two of the inertial probes tested were provided with venturi flow meters to monitor flow. All three probes used vacuum eductors to draw flow through the filter element. 


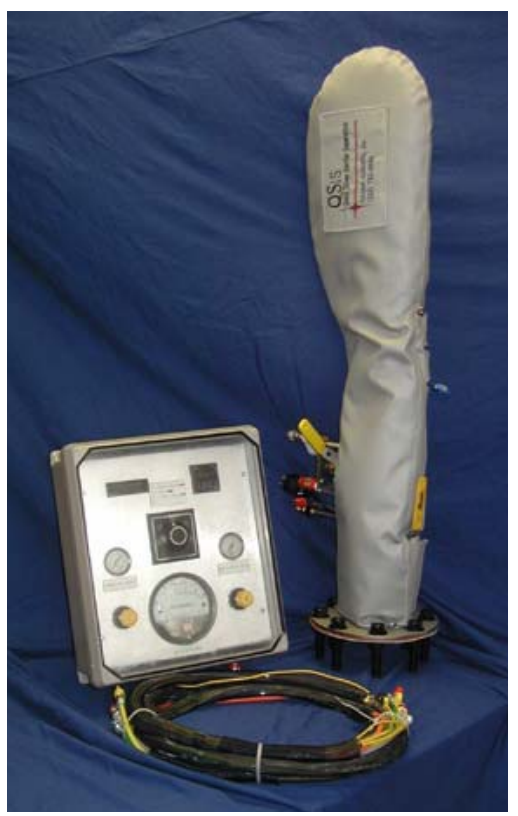

Apogee QSIS Probe

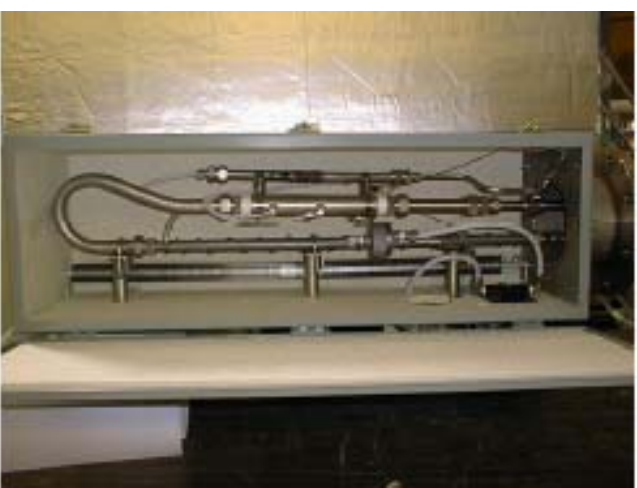

Baldwin Probe (shown with cover open)

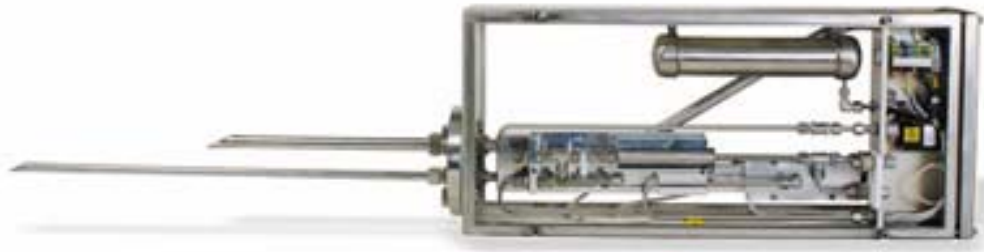

Thermo Electron (EPM Environmental) (shown with covers removed)

Figure 1. Photographs of the inertial separation probes included in the evaluation program. 


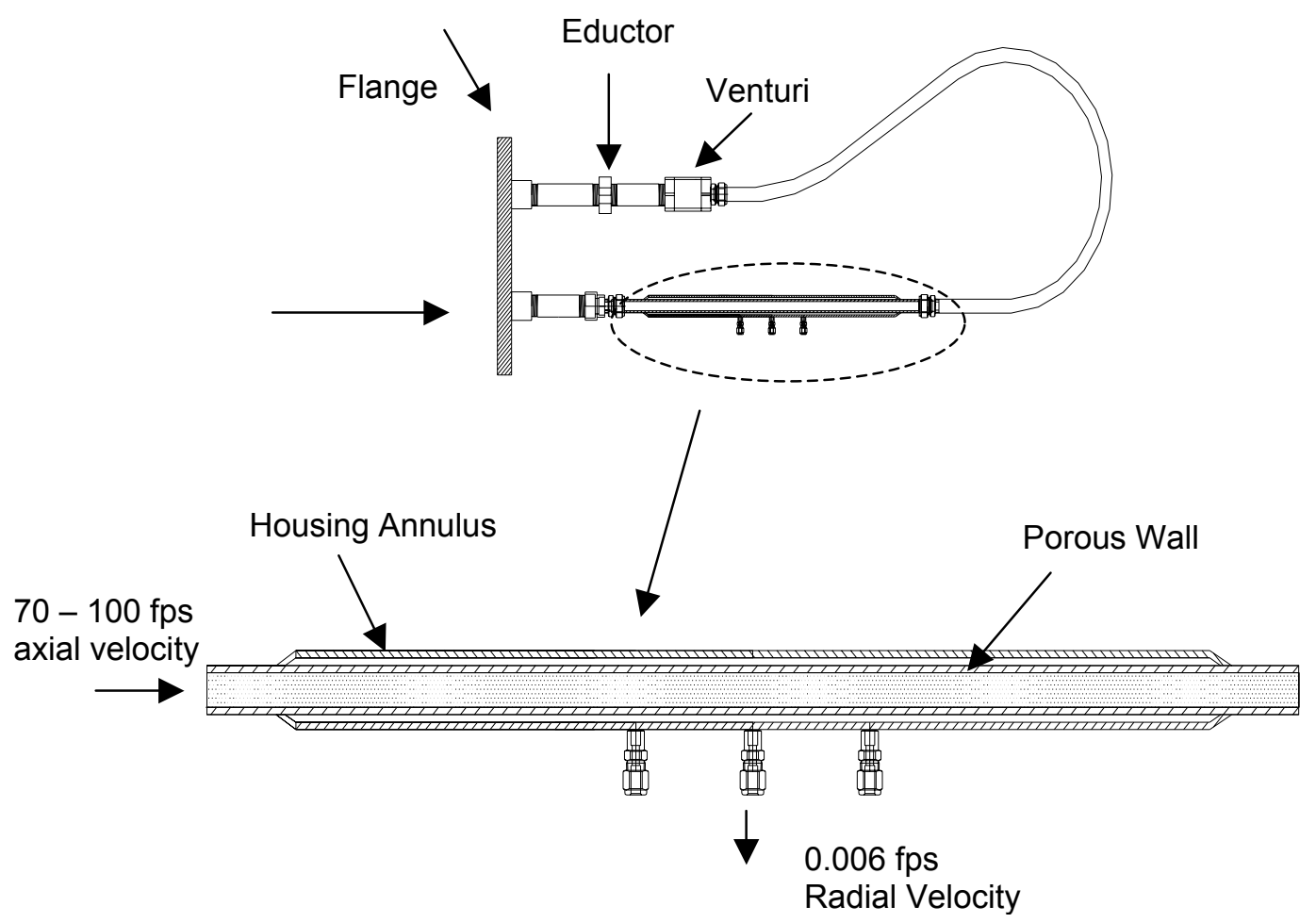

Figure 2. General arrangement sketch of the inertial probe assembly and filter.

\section{Sample Pretreatment System}

ADA-ES fabricated the flue gas pretreatment system. The system consists of two sampling trains, each incorporating two impingers followed by a thermoelectric cooler to dry the sample. For the total vapor-phase mercury sampling train, a solution of mildly acidified stannous chloride is continuously introduced to the first impinger and spent solution is continuously removed. The stannous chloride converts all vapor-phase mercury to the elemental form. A solution of sodium hydroxide is introduced into the second impinger. For elemental mercury measurements, the stannous chloride impinger is replaced with a solution of potassium chloride to remove oxidized forms of mercury. The impingers are located at the sample port on the extraction probe to minimize transport losses.

\section{Sample Transport}

The mercury instrument was installed in a sampling trailer on the ground level below the sample extraction location. The sample was transported to the instrument through 50 feet of heated $\left(300^{\circ} \mathrm{F}\right){ }^{1 / 4}$-inch PFA tubing. The flow through each sample line was maintained at nominally $1.5 \mathrm{slpm}$. The mercury analyzer drew a slipstream from the main sample flow for analysis. 


\section{Mercury Analyzer}

A Tekran Model 2537A Mercury Vapor Analyzer was used for this program. The instrument uses two mercury traps containing ultra-pure gold adsorbent. The amalgamated mercury is thermally desorbed for detection using Cold-Vapor Atomic Fluorescence Spectrometry (CVAFS). Continuous sampling is achieved by alternating the traps between collecting and desorbing mercury, with one trap always in the collection mode and one trap always in the measurement mode. Flow through the trap was maintained at $250 \mathrm{cc} / \mathrm{min}$.

\section{Mercury Analyzer Calibration System}

The Tekran instrument has provisions for two methods of calibration: manual injection or an internal elemental mercury permeation tube for automatic instrument calibrations. The permeation tube option was used during these tests.

\section{Elemental and Oxidized Mercury Spiking Systems}

Two systems were used during the program to introduce elemental and oxidized mercury into the probes upstream of the inertial filter. The elemental spiking system was a PSA 10.534 Mercury Calibration System fabricated by P S Analytical. The PSA 10.534 provides a wide range of mercury concentrations by altering the temperature of a mercury reservoir and varying the gas flowrate through the reservoir. The mercury reservoir is constructed by impregnating elemental mercury on an inert substrate. The gas passing over the substrate becomes saturated with mercury at the reservoir temperature.

The oxidized mercury source was a Hot-Vapor Calibration (HOVACAL ) system manufactured by IAS GmbH (distributed in the U.S. by EcoChem Analytics). For this system, a solution of mercuric chloride is injected onto a heated head to evaporate the solution. Nitrogen carries the gaseous mercuric chloride into the bulk gas. A photo of the HOVACAL installed at the site is shown in Figure 3. The heated head, disconnected from the injection port on the probe, is shown in the right of the photo. The liquid calibration solution is delivered to the head with a peristaltic pump. The pump flow rate is verified using a loss-of-weight balance (shown in upper right of photo). The peristaltic pump feed rate, nitrogen flow rate, and the head temperature are controlled with a touch-screen interface shown on the front of the HOVACAL unit. 


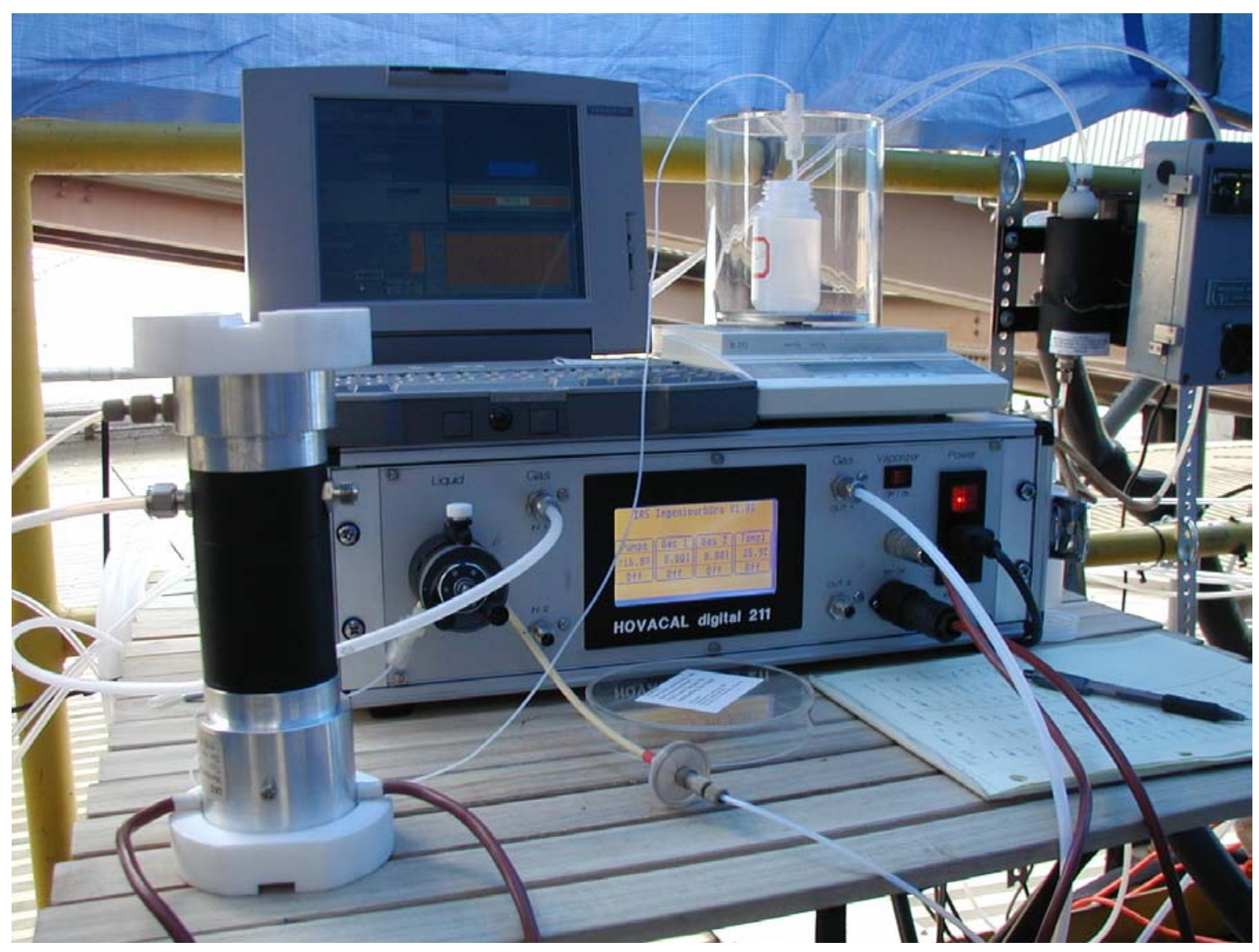

Figure 3. HOVACAL installed at Pleasant Prairie.

\section{Evaluation Program}

The goal of the evaluation program was to determine the effectiveness of inertial separation probes for both elemental and oxidized mercury transport in a relatively clean gas stream, and to qualitatively assess their ability to inertially separate particles with a high affinity for mercury with minimal sampling artifacts. The general plan was to alternately spike the probes with elemental and oxidized mercury ahead of the filter and then measure the resulting mercury concentrations, and to dope the probes with activated carbon and monitor the effect.

\section{Probe Preparation}

Flow Measurement

The oxidized and elemental mercury spiking systems were configured to introduce a small volume of concentrated vapor-phase mercury into the bulk probe flow upstream of the inertial filter. The flow through the probe was monitored to determine the expected mercury concentration in the bulk flow downstream of the spike.

Each probe was retrofitted with a venturi flow meter to monitor the gas flow through the probes. The venturi flow meters were installed at the end of the exhaust return pipe to 
eliminate the need to modify the overall probe design or operation. Since compressed air is introduced into the vacuum eductors upstream of the exhaust venturis, it was also necessary to measure the compressed air flow to determine the actual flow through the inertial separation portion of the probes. Two of the probes also included integral venturi flow meters.

\section{Gas Spiking Ports}

The Apogee and Thermo probes were retrofitted with spiking ports immediately upstream of the inertial filter to allow spiking with elemental and oxidized mercury. Because high concentrations of oxidized mercury can be difficult to transport, the length of the spike transport line was minimized to prevent losses. The spiking port on two of the probes (the small probe and one of the larger probes) was retrofitted so that the HOVACAL head could be connected directly to the port. The spiking port for the other large probe was located inside the heated enclosure requiring nominally 18 inches of PFA Teflon ${ }^{\text {TM }}$ and 6 inches of coated stainless steel transport line prior to entering the bulk probe flow.

Probe Extensions (Stingers)

A 6-foot stinger was installed on the inlet of each extraction probe. For the two higher-flow probes, $3 / 4$-inch pipe was used. Baldwin provided a Durinert ${ }^{\mathrm{TM}}$-coated stinger for use with their probe. One-half inch tube was used for the stinger on the lower-flow probe.

Activated Carbon Injection Line

A $1 / 4$-inch stainless steel carrier line was installed along the stinger for activated carbon injection. One end of this line extended into the tip of the stinger. The opposite end terminated outside of the flange to allow doping with activated carbon.

A photograph of the Baldwin probe with the exhaust venturi, probe extension, and calibration line is shown in Figure 4.

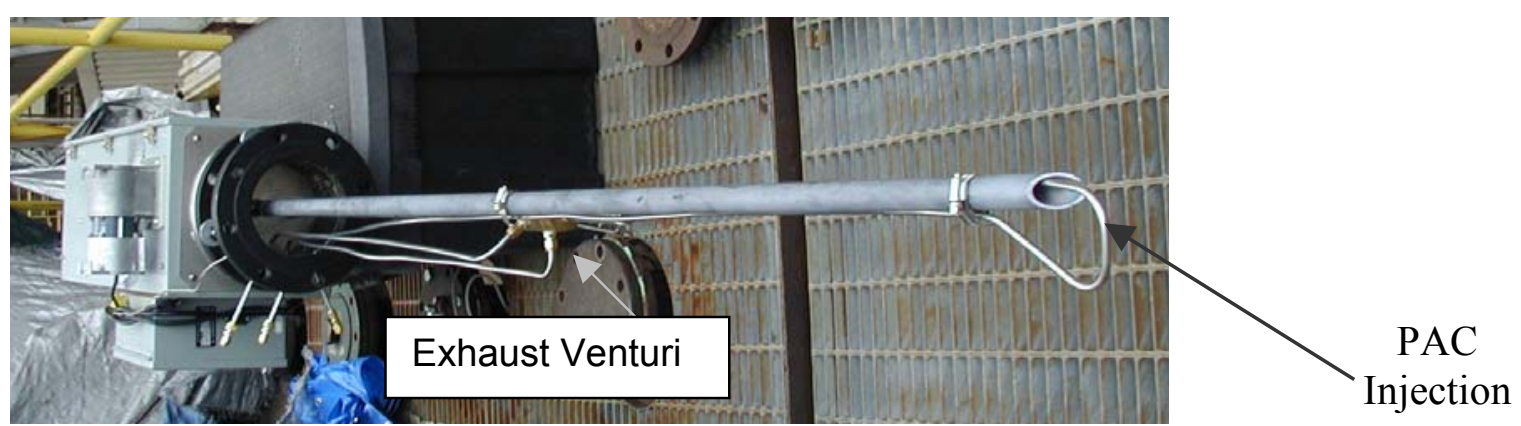

Figure 4. Photo of Baldwin probe with additional monitoring equipment installed. 


\section{Test Protocol}

The exhaust venturi flow meters and integral venturi flow meters were calibrated using a laminar flow element prior to testing. These calibrations were used to determine the expected vapor-phase mercury concentrations during elemental and oxidized mercury spike test periods. The probes were installed and operating at the manufacturer's recommended operating conditions (flow and temperature) for at least 24 hours prior to testing.

At the beginning of each test day, the Tekran instrument was calibrated with the on-board permeation device. Following calibration, baseline mercury measurements were made to establish the vapor-phase mercury concentration and speciation in the duct. Pleasant Prairie burns a PRB coal. The mercury concentration was fairly stable and the mercury was primarily in the elemental form (typically $>80 \%$ ).

After establishing the baseline conditions, the output from the PSA 10.534 was connected to the calibration port on the extraction probe. Based upon the saturator temperature and flowrate through the PSA 10.534, the mercury introduced to the probe ( $\mathrm{ng} / \mathrm{min}$ ) could be calculated. The expected mercury concentration was determined by adding the mercury mass injection rate divided by the probe flow to the baseline duct concentration. Each probe was evaluated at 300 and $400^{\circ} \mathrm{F}$.

Following performance evaluations with elemental mercury, the probes were spiked with oxidized mercury from the HOVACAL system. The concentration of oxidized mercury was calculated using the injection rate of the $\mathrm{HgCl}_{2}$ solution and the flow rate through the probe. Tests were conducted at 300 and $400^{\circ} \mathrm{F}$ to establish the temperature stability of the probes for oxidized mercury measurements.

The final test was designed to determine the inertial separation effectiveness. Because the three probes were installed at the outlet of the electrostatic precipitator at Pleasant Prairie, the fly ash loading to the probes was quite low. This provided a good opportunity to evaluate the probe for elemental and oxidized mercury measurements without concern for in-duct reactions with the fly ash. However, this test location and the nature of the fly ash at Pleasant Prairie (relatively low affinity for mercury) did not challenge the probes for their ability to adequately separate particulate matter while minimizing the sampling artifacts.

For the final test, NORIT FGD activated carbon was introduced by batch injection into the tip of the probe extension. The injection rate was equivalent to nominally $45 \mathrm{lb} / \mathrm{MMacf}$, which is roughly twice the maximum injection rate economically feasible for an ESP application. The injection was maintained for 30 seconds and repeated at two different operating temperatures $\left(300\right.$ and $\left.400^{\circ} \mathrm{F}\right)$. Total and elemental mercury measurements were made during and following injection. The residence time in the probe extensions was less than 0.15 seconds for most of the test conditions. 


\section{Results}

The baseline vapor-phase mercury concentration in the flue gas during testing ranged from 9 to $12 \mu \mathrm{g} / \mathrm{Nm}^{3}$. The flue gas flowrate through the larger probes ranged from 10 to $11.5 \mathrm{acfm}$. The flowrate through the smaller probe ranged from 2.25 to $3.0 \mathrm{acfm}$. The large probes were operated at their maximum design velocity and the small probe was operated slightly above the design velocity of the system.

\section{Elemental Mercury Spiking}

All three probes performed well when elemental mercury was introduced upstream of the inertial filter. The recovery of total mercury was quite good and well within the measurement uncertainty of the probe flow. Both of the uncoated stainless steel probes demonstrated some oxidation of the elemental mercury spike. The larger probe demonstrated somewhat more oxidation $\left(11 \%\right.$ at $300^{\circ} \mathrm{F}$ and $19 \%$ at $\left.400^{\circ} \mathrm{F}\right)$. The smaller uncoated probe demonstrated slight ( 3 to $5 \%$ ) oxidation at 300 and $400^{\circ} \mathrm{F}$. The Durinert ${ }^{\mathrm{TM}}$-coated probe did not produce any measurable oxidation at either temperature. An example of the mercury concentrations measured during an elemental mercury-spiking period is shown in Figure 5.

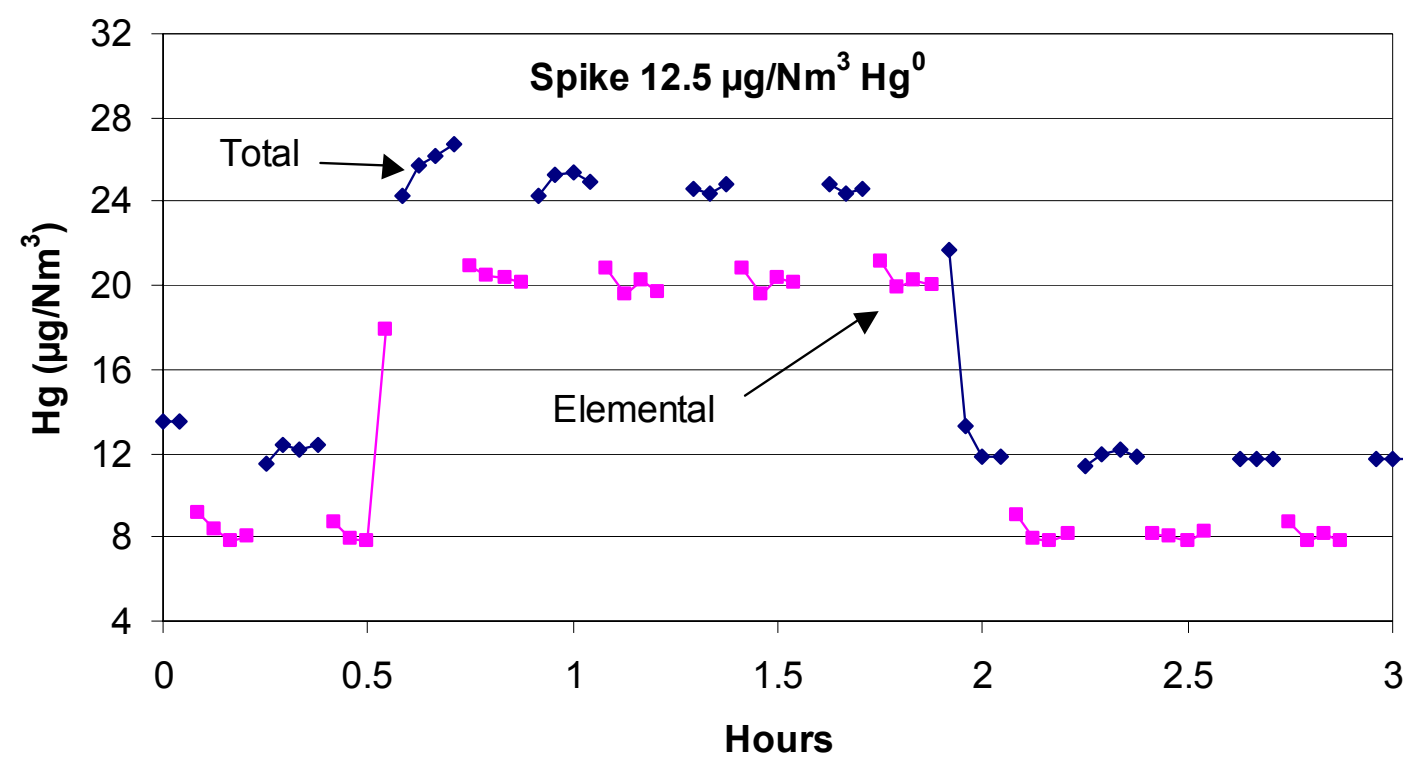

Figure 5. Example of an elemental mercury spike.

\section{Oxidized Mercury Spiking}

The recovery of oxidized mercury was very good ( $>90 \%$ of the expected concentration) on both probes that could be close-coupled to the HOVACAL head. For the larger probe, the recovery was slightly lower at $300^{\circ} \mathrm{F}$ than $400^{\circ} \mathrm{F}$. There was no measurable difference in performance between 300 and $400^{\circ} \mathrm{F}$ for the smaller probe. The smaller probe also resulted in a higher fraction of the sample measured as oxidized ( $>95 \%$ of expected). The oxidized mercury measured with the larger probe was 82 to $85 \%$ of the expected concentration. An 
example of the mercury concentrations measured during an oxidized mercury-spiking period is shown in Figure 6.

The oxidized mercury spike test for the probe with the calibration port extension was not as successful as the other two probes. Nominally $50 \%$ of the spiked concentration was measured when using this probe, and only 30 to $40 \%$ of the expected concentration was measured as oxidized mercury. Due to the difficulties transporting oxidized mercury, poor performance may be due to difficulties transporting the spike sample to the calibration port on the probe and not necessarily due to any other aspect of the probe design. Modifications to allow direct coupling of the HOVACAL head to this probe are required to allow an appropriate evaluation of oxidized mercury spiking.

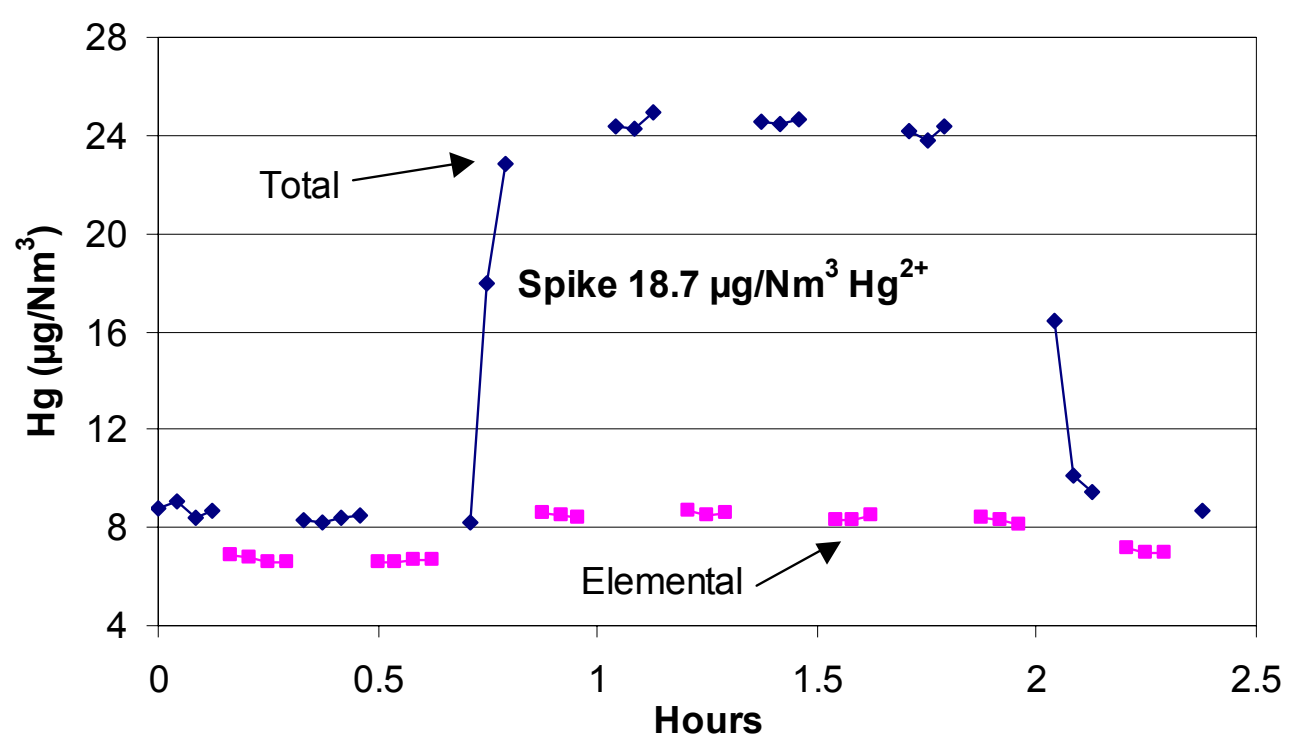

Figure 6. Example of an oxidized mercury spike.

\section{Doping with Activated Carbon}

Following characterization with elemental and oxidized mercury spikes, each of the probes was challenged with activated carbon to qualitatively assess the ability of the probes to inertially separate particulate matter with an affinity for mercury.

Both large probes demonstrated a rapid drop in mercury concentration following injection. The concentration immediately following injection was 15 to $60 \%$ lower than the initial concentration. The total mercury concentration on one of the large probes returned immediately to the baseline concentration following injection. However, some activated carbon remained on the filter as evidenced by the increased oxidation across the probe (typically $20 \%$ additional oxidation following injection). This behavior is shown for probe "C" in Figure 7. In the figure, a batch of activated carbon is added in three distinct episodes. Following testing, the sampling train is moved to another probe. Note the decrease in the 
fraction of elemental mercury following activated carbon injection. Also note that the elemental mercury is equal to the total mercury when measured through probe "B". No carbon injection episodes are shown for probe "B".

The total mercury concentration measured with the coated probe did not immediately return to baseline concentrations but remained suppressed for up to an hour following activated carbon injection. The fraction of oxidized mercury also increased across this probe following each injection episode.

No drop in mercury concentration or increase in oxidation was noted across the small probe.

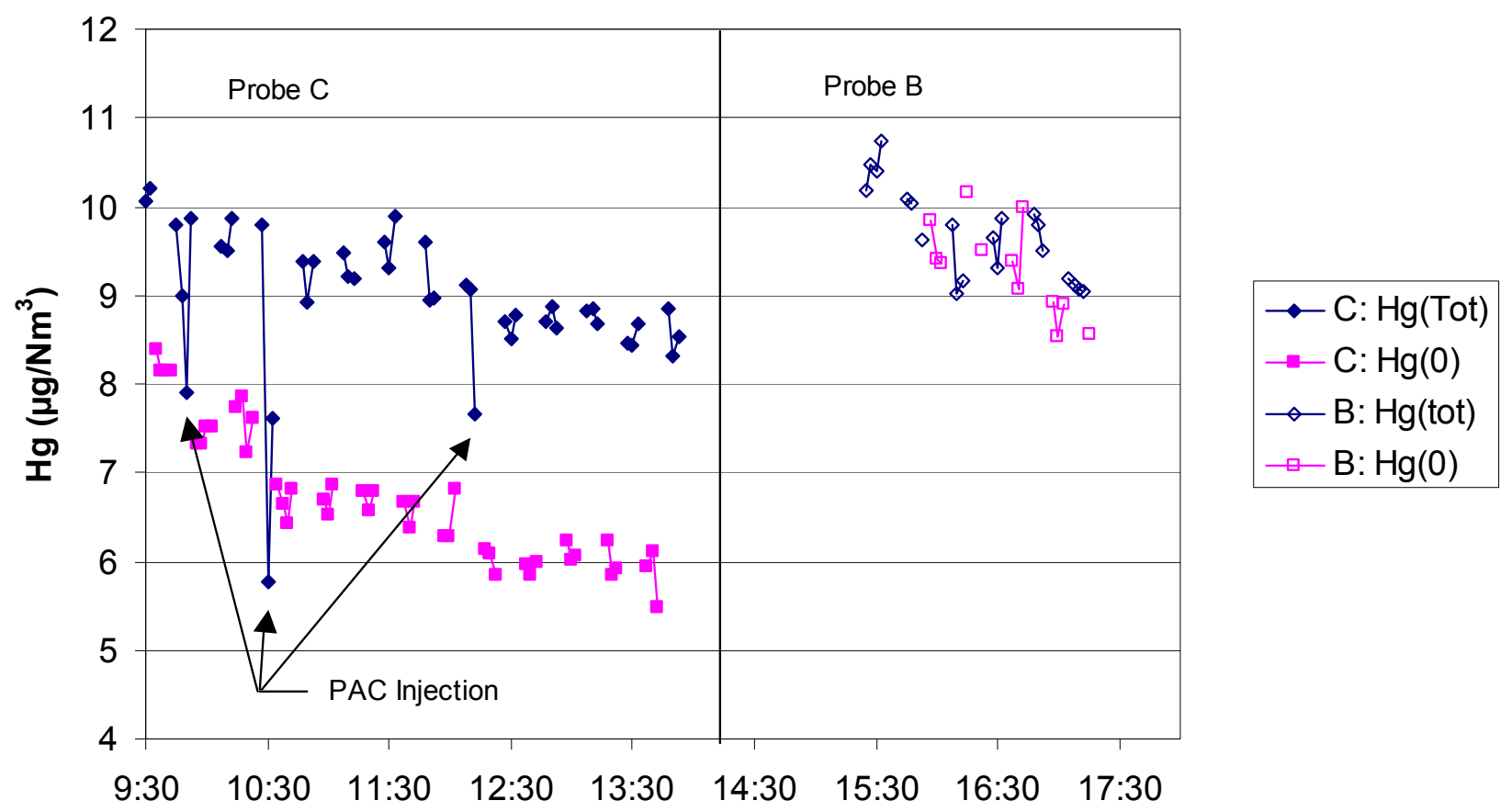

Figure 7. Effect of activated carbon injection into probe "C" on total and elemental mercury concentrations. 


\section{Conclusions}

- All three probes demonstrated good performance and could be incorporated for use in a total vapor-phase mercury CEM system.

- The uncoated stainless steel probes demonstrated a potential to oxidize mercury, with the larger probe demonstrating more oxidation than the smaller probe (19\% oxidation with large probe and $5 \%$ oxidation with small probe at $400^{\circ} \mathrm{F}$ ).

- The recovery of oxidized mercury was very good $(>90 \%$ of the expected concentration) on both probes that could be close-coupled to the HOVACAL oxidized mercury spiking system. Due to difficulties transporting oxidized mercury to the spiking port on the third probe, the oxidized mercury performance for this probe is inconclusive.

- The probes did not appear to be overly sensitive to operating temperature in the range of 300 to $400^{\circ} \mathrm{F}$ (there was a slight increase in oxidation noted on uncoated probes at $400^{\circ} \mathrm{F}$ compared to $300^{\circ} \mathrm{F}$ ).

- Some activated carbon appeared to deposit on the larger probes as demonstrated by an initial drop in the measured mercury concentration and either a prolonged oxidation effect (activated carbon is known to oxidize mercury after reaching saturation capacity) or a period of suppressed total mercury following injection.

- The smaller probe appeared to be effective at minimizing the effect of high-activity particulate (activated carbon) on vapor-phase mercury measurements.

\section{Additional Observations}

- An elemental mercury doping system should be incorporated into all mercury CEMs and dynamic spiking should be done on a regular basis to assure proper system performance, particularly when probes are used in gas with active particulate matter when speciated mercury measurements are necessary.

- Dynamic spiking should be conducted in the flue gas matrix to minimize variations in flue gas chemistry that may affect the performance of the pretreatment system or transport assembly.

- Bottled calibration gases may not be appropriate for this application due to the low mercury concentration limits of bottled gases.

- Spiking with oxidized mercury should be conducted on a periodic basis to ensure proper system operation. Additional tests must be conducted to ensure stability of HOVACAL and develop a more robust system, or other systems must be demonstrated. 


\section{References}

Apogee Scientific, Inc., 2985 South Oxford Ave, Unit 1, Englewood, CO 80110

Tel (303) 783-9599

www.apogee-sci.com

Baldwin, Inc., 895 E. Patriot Blvd., Suite 107, Reno, NV 89511

Tel (775) 850-1800 / (888) 234-7366 (toll-free U.S.)

www.baldwinusa.com

EcoChem Analytics, 202 Reynolds, League City, TX 77573

Tel (281)338-9888 Fax: (281) 332-6152

www.echochem.biz

P S Analytical, Ltd, Arthur House, Crayfields Industrial Estate, Main Road, Orpington, Kent BR5 3HP, UK

Tel (Int): +44 (0) 1689891211

www.psanalytical.com

Tekran Inc., 330 Nantucket Boulevard, Toronto, Ontario M1P 2P4

www.tekran.com

Thermo Electron Corporation, Environmental Instruments Division, Air Quality Instruments, Twenty-Seven Forge Parkway, Franklin, MA

Tel: Toll-Free (866) 282-0430 or (508) 520-0430

www.thermo.com/aqp 